Article

\title{
Effect of $\mathrm{H}_{2} \mathrm{O}$ and $\mathrm{O}_{2}$ on the Adsorption and Degradation of Acetaldehyde on Anatase Surfaces-An In Situ ATR-FTIR Study
}

\author{
Stephanie Melchers ${ }^{1, *}$, Jenny Schneider ${ }^{1}$, Alexei V. Emeline ${ }^{2}$ and Detlef W. Bahnemann ${ }^{1,2}$ \\ 1 Institut für Technische Chemie, Leibniz Universität Hannover, Callinstr. 5, 30167 Hannover, Germany; \\ schneid@iftc.uni-hannover.de (J.S.); bahnemann@iftc.uni-hannover.de (D.W.B.) \\ 2 Laboratory "Photoactive Nanocomposite Materials", Saint-Petersburg State University, Ulyanovskaya str. 1, \\ Peterhof, Saint-Petersburg 198504, Russia; alexei.emeline@spbu.ru \\ * Correspondence: melchers@iftc.uni-hannover.de
}

Received: 10 September 2018; Accepted: 21 September 2018; Published: 25 September 2018

\begin{abstract}
The effect of $\mathrm{H}_{2} \mathrm{O}$ and $\mathrm{O}_{2}$ on the adsorption and degradation of gaseous acetaldehyde on the anatase $\mathrm{TiO}_{2}$ surface has been studied, in the dark and upon UV illumination, at ambient temperatures. The processes occurring at the surface have been elucidated by means of in situ ATR-FTIR (Attenuated Total Reflection-Fourier Transform Infrared) spectroscopy, while gas detectors allowed the analysis of the adducts and products in the gas phase. In the dark and under dry conditions acetaldehyde reacts independently of the atmosphere, upon aldol condensation to crotonaldehyde. However, under humid conditions, this reaction was prevented due to the replacement of the adsorbed acetaldehyde molecules, by water molecules. Upon UV illumination under oxygenic conditions, acetaldehyde was decomposed to acetate and formate. Under an $\mathrm{N}_{2}$ atmosphere, the formation of acetate and formate was observed during the first hour of illumination, until all adsorbed oxygen had been consumed. In the absence of molecular oxygen acetate, methane, and $\mathrm{CO}_{2}$ were detected, the formation of which most likely involved the participation of the bridging $\mathrm{O}$ atoms, within the $\mathrm{TiO}_{2}$ lattice.
\end{abstract}

Keywords: acetaldehyde; degradation; adsorption; oxygen; ATR-FTIR; anatase; $\mathrm{TiO}_{2}$

\section{Introduction}

Nowadays, the demand for clean and fresh indoor air is a public health issue. Herein, one major indoor air pollutant is acetaldehyde, which is a potential human carcinogen [1], whose maximum occupational exposure levels are set in Europe, and in the USA [2,3]. In this context, photocatalysis might be a sustainable and environmentally friendly solution to decrease the concentration of acetaldehyde. Upon $\mathrm{UV}(\mathrm{A})$ illumination, $\mathrm{TiO}_{2}$ is able to catalyze the decomposition of organic compounds, yielding $\mathrm{CO}_{2}, \mathrm{H}_{2} \mathrm{O}$, and traces of mineral acids as reaction products [4]. The photocatalytic efficiency of this process can be further improved, provided that the reaction mechanism and the limitations are known.

In situ ATR-FTIR (Attenuated Total Reflection-Fourier Transform Infrared) spectroscopy is an established technique that provides a deeper understanding of the interfacial processes occurring at the semiconductor/water interface. This technique allows the monitoring of the molecule adsorption from gaseous and from liquid phase on solid surfaces, as well as the detection of intermediates and products of photocatalytic processes [5,6].

Employing FTIR spectroscopy it has been reported that under dry conditions in the dark an aldol condensation of two acetaldehyde molecules occurs on the $\mathrm{TiO}_{2}$ surface resulting in the formation of crotonaldehyde [7]. Subsequently, 3-Hydroxybutanal has also been identified as a short-lived intermediate [8,9]. Batault et al. [10] investigated the adsorption of acetaldehyde on the $\mathrm{TiO}_{2}$ surface 
under dry and humid conditions. These authors reported that under dry conditions acetaldehyde is mostly irreversibly adsorbed on the $\mathrm{TiO}_{2}$ surface, while under $50 \%$ relative humidity ( $\mathrm{RH}$ ) acetaldehyde adsorption only occurs as a reversible physical adsorption. The effect of humidity on the formation of crotonaldehyde was not discussed.

Ohko et al. [11] and Muggli et al. [12] investigated the photocatalytic degradation of acetaldehyde over $\mathrm{TiO}_{2}$, under weak UV illumination, in the presence of $\mathrm{O}_{2}$. These authors proposed the reaction mechanism shown in Figure 1. According to this mechanism, acetaldehyde is first oxidized to acetic acid, followed by the decarboxylation of acetic acid, yielding $\mathrm{CO}_{2}$. The remaining methyl radical is transformed into formaldehyde which can be further oxidized to formic acid and eventually to $\mathrm{CO}_{2}$.

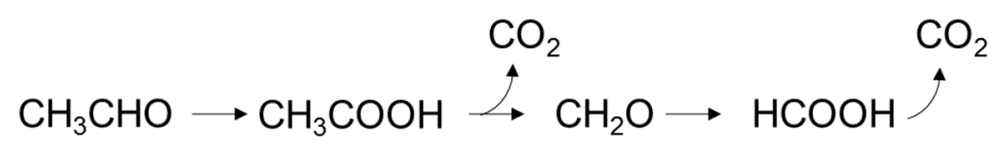

Figure 1. The proposed reaction mechanism for the photocatalytic degradation of acetaldehyde by $\mathrm{TiO}_{2}$, under weak UV illumination. First, acetaldehyde is oxidized to acetic acid, which can be transformed into $\mathrm{CO}_{2}$ and formaldehyde. Formaldehyde is then oxidized to formic acid and eventually to $\mathrm{CO}_{2}$.

The previously mentioned reaction pathway was proposed for the degradation of acetaldehyde in the presence of $\mathrm{O}_{2}$. To the best of our knowledge, the degradation of gaseous acetaldehyde over $\mathrm{TiO}_{2}$ in the absence of molecular $\mathrm{O}_{2}$ has not been reported yet. In photocatalysis $\mathrm{O}_{2}$ usually plays an important role preventing the charge carrier recombination by trapping the photogenerated electrons upon formation of a superoxide radical $\mathrm{O}_{2}{ }^{-}$which can be further reduced leading to the formation of a strong oxidant that is the hydroxyl radical. Furthermore, $\mathrm{O}_{2}$ is involved in free radical chain reactions occurring during the photocatalytic degradation of organic compounds [13].

In this study, the effect of water vapor on the adsorption of acetaldehyde and on the formation of crotonaldehyde on the $\mathrm{TiO}_{2}$ surface were investigated, in the dark. Furthermore, the photocatalytic degradation of gaseous acetaldehyde over $\mathrm{TiO}_{2}$ was investigated, upon UV illumination in the $\mathrm{N}_{2}$ atmosphere, in order to examine the photocatalytic degradation mechanism of acetaldehyde, in the absence of $\mathrm{O}_{2}$. In situ ATR-FTIR spectra were recorded to elucidate the processes occurring on the $\mathrm{TiO}_{2}$ surface while adducts and evolved products in the gas phase, were analyzed by mass spectrometry (MS) and GC.

\section{Results and Discussion}

\subsection{Effect of $\mathrm{H}_{2} \mathrm{O}$ on the Acetaldehyde Adsorption}

Figure 2 shows the change in the acetaldehyde concentration, over time, measured in the presence of air, in dry and in humid conditions, in the dark. When a $\mathrm{TiO}_{2}$ film was treated with $1000 \mathrm{ppb}$ gaseous acetaldehyde, under dry conditions, a decrease in the concentration of acetaldehyde, from $1000 \mathrm{ppb}$ to about $700 \mathrm{ppb}$ was observed (Figure 2, left). Surprisingly, the reduced concentration remained constant even after several hours of treatment (Figure S1). In contrast, the presence of humid air led to a short lowering of the acetaldehyde concentration, indicating an adsorption on the anatase surface, until all adsorption sites were occupied, and the initial concentration was reached again (Figure 2, right).

ATR-FTIR analysis of $\mathrm{a} \mathrm{TiO}_{2}$ film treated with acetaldehyde was performed to figure out the reason behind the constant low amount of acetaldehyde detected at the reactor outlet, under dry conditions, in the dark. Figure 3 shows the FTIR spectra in the wavenumber range between $1000 \mathrm{~cm}^{-1}$ and $1800 \mathrm{~cm}^{-1}$, which were recorded during the gaseous purging of acetaldehyde over a $\mathrm{TiO}_{2}$ film, for two hours, in the dark. Different bands appeared and increased in intensity, during the acetaldehyde dosing. In Table 1, the positions of the bands are assigned to the specific molecular vibrations of acetaldehyde and crotonaldehyde. These band assignments were in accordance to literature, where an adsorption of acetaldehyde on $\mathrm{TiO}_{2}$ had also been reported by the FTIR spectroscopy $[9,14,15]$. 
The carbonyl group of acetaldehydes could form hydrogen bonds with the surface hydroxyl groups of the $\mathrm{TiO}_{2}$. It could be stabilized on the $\mathrm{TiO}_{2}$ surface, via an interaction between the oxygen lone pair, with the Lewis surface sites of $\mathrm{TiO}_{2}[14,16]$, the corresponding vibrational position was located at $v(\mathrm{C}=\mathrm{O}) 1699 \mathrm{~cm}^{-1}$. Additional characteristic bands of acetaldehyde, such as the $\rho\left(\mathrm{CH}_{3}\right)$ and $v(\mathrm{C}-\mathrm{C})$ were also detected and these can be seen in Table 1 .
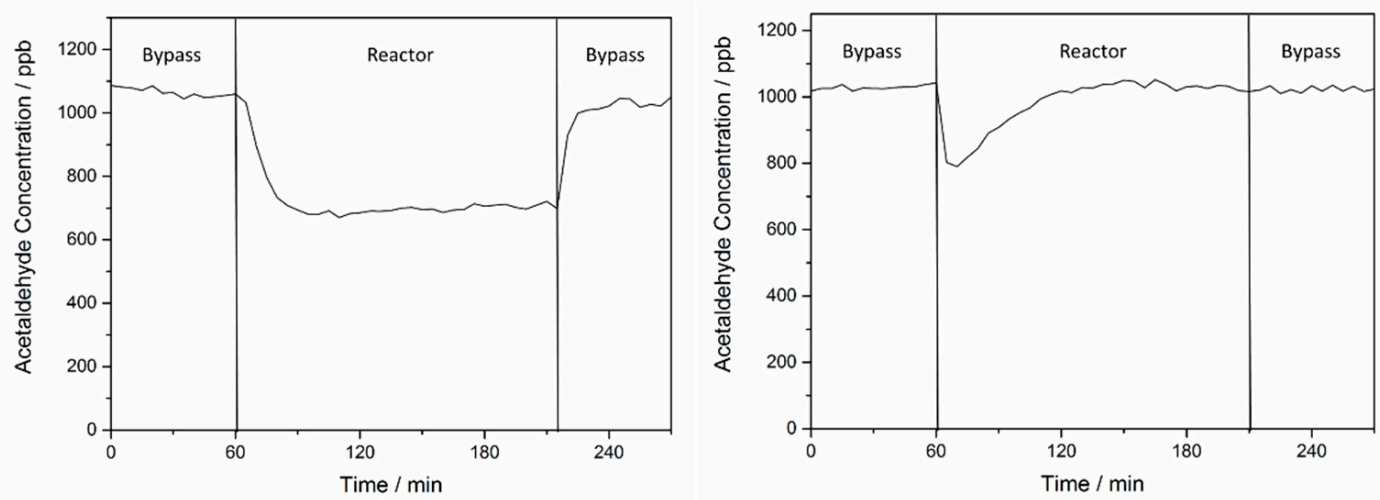

Figure 2. The concentration of acetaldehyde as a function of time, under dry (Left) and humid (Right) conditions, in air and in the dark. During the first $60 \mathrm{~min}$, the gas flow was held constant, in bypass mode. Afterward, it was directed over a $\mathrm{TiO}_{2}$ film, for $2.5 \mathrm{~h}$, in the dark, before it was turned back to the bypass mode again.

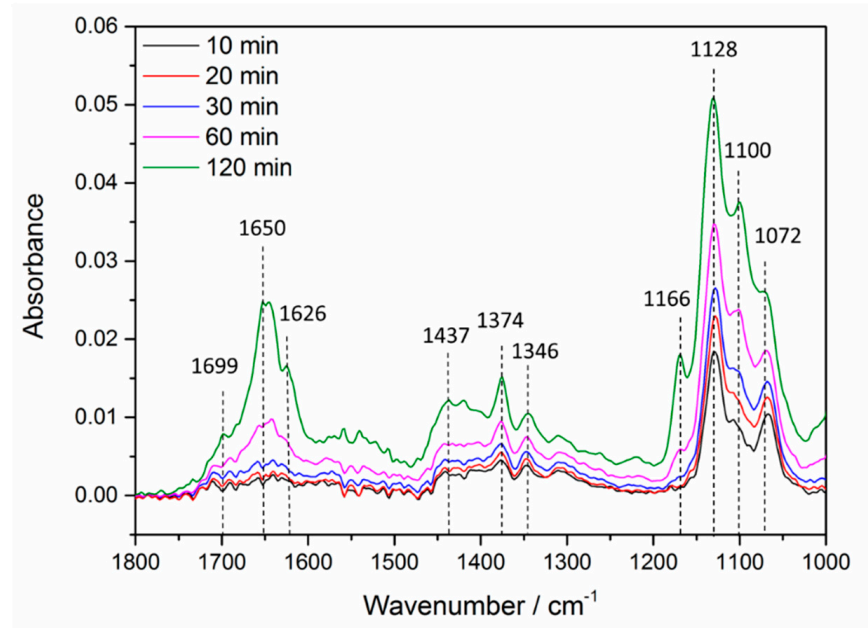

Figure 3. ATR-FTIR spectra recorded during the gaseous treatment of acetaldehyde in air over a $\mathrm{TiO}_{2}$ film, for $2 \mathrm{~h}$, under dry conditions, in the dark.

Table 1. Vibrational frequencies and mode assignments of the observed FTIR bands $\left(\mathrm{cm}^{-1}\right)$ during purging of acetaldehyde in air, over a $\mathrm{TiO}_{2}$ film in the dark.

\begin{tabular}{cc}
\hline Position/cm & Assignment $[8,17,18]$ \\
\hline 1072 & $\rho\left(\mathrm{CH}_{3}\right) \mathrm{Ti}-\mathrm{O}=\mathrm{CHCH}_{3}$ \\
1100 & $\rho\left(\mathrm{CH}_{3}\right) \mathrm{Ti}-\mathrm{O}=\mathrm{CH}(\mathrm{CH})_{2} \mathrm{CH}_{3}$ \\
1128 & $v(\mathrm{C}-\mathrm{C}) \mathrm{Ti}-\mathrm{O}=\mathrm{CHCH}_{3}$ \\
1166 & $v(\mathrm{C}-\mathrm{C}) \mathrm{Ti}-\mathrm{O}=\mathrm{CH}(\mathrm{CH})_{2} \mathrm{CH}_{3}$ \\
1346 & $\delta\left(\mathrm{CH}_{3}\right) \mathrm{Ti}-\mathrm{O}=\mathrm{CHCH}_{3}$ \\
1374 & $\delta(\mathrm{CH}) \mathrm{Ti}-\mathrm{O}=\mathrm{CHCH}{ }_{3}$ \\
1437 & $\delta\left(\mathrm{CH}_{3}\right) \mathrm{Ti}-\mathrm{O}=\mathrm{CH}(\mathrm{CH})_{2} \mathrm{CH}_{3}$ \\
1626 & $v(\mathrm{C}=\mathrm{C}) \mathrm{Ti}-\mathrm{O}=\mathrm{CH}(\mathrm{CH})_{2} \mathrm{CH}_{3}$ \\
1650 & $v(\mathrm{C}=\mathrm{O}) \mathrm{Ti}-\mathrm{O}=\mathrm{CH}(\mathrm{CH})_{2} \mathrm{CH}_{3}$ \\
1699 & $v(\mathrm{C}=\mathrm{O}) \mathrm{Ti}-\mathrm{O}=\mathrm{CHCH} H_{3}$ \\
\hline
\end{tabular}


Besides acetaldehyde, bands characteristic for the molecular vibrations of crotonaldehyde were observed. Singh et al. [8] showed by IR spectroscopy, that an aldol condensation of two acetaldehyde molecules which then forms crotonaldehyde, takes place on the $\mathrm{TiO}_{2}$ surface. Here, it is noteworthy to mention, that the $\rho\left(\mathrm{CH}_{3}\right), v(\mathrm{C}-\mathrm{C})$, and $v(\mathrm{C}=\mathrm{O})$ showed a higher increase in intensity during the second hour of treatment, as compared to the first hour (see pink and green curve). This could be explained by the fact that for the formation of crotonaldehyde, two acetaldehyde molecules needed to be adsorbed on the anatase surface, reacting via an aldol condensation. A higher amount of crotonaldehyde was formed during the second hour of treatment, because a certain time was required to achieve a sufficient adsorption of acetaldehyde on the $\mathrm{TiO}_{2}$ surface. Taking into account the continuous small acetaldehyde concentration of $700 \mathrm{ppb}$ measured at the reactor exit (see Figure 2, left), it was proposed that the evolved crotonaldehyde was continuously desorbed from the $\mathrm{TiO}_{2}$ surface and replaced by the new acetaldehyde molecules, which again reacted to the crotonaldehyde (see Figure 4).

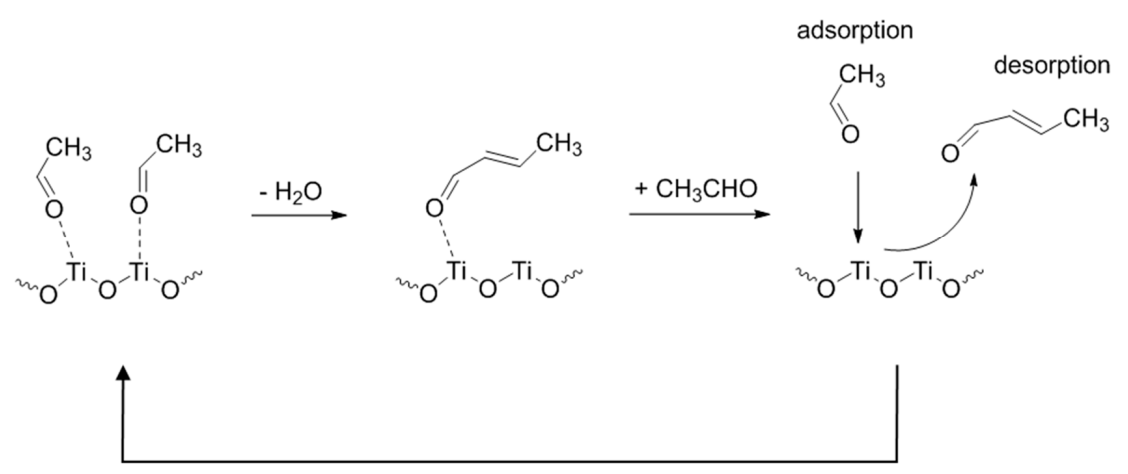

Figure 4. Adsorption and reaction of acetaldehyde on the anatase surface, in the dark. Acetaldehyde molecules were adsorbed on the $\mathrm{TiO}_{2}$ surface and reacted, via an aldol condensation, to the crotonaldehyde. Crotonaldehyde was desorbed from the surface and was replaced by new acetaldehyde molecules, which further reacted with each other.

This assumption was confirmed by mass spectrometry (MS) analysis. Herein, $50 \mathrm{ppm}$ of acetaldehyde were directed over an anatase film and the gas at the outlet was continuously analyzed by MS (Figure S2). The QMS (quadrupole mass spectrometer) signal of the mass of $41 \mathrm{~m} / \mathrm{z}$, corresponding to the crotonaldehyde, steadily increased until it reached a stable value after $15 \mathrm{~h}$. When the acetaldehyde gas flow was turned off, the QMS signal decreased again. Accordingly, crotonaldehyde was desorbed from the anatase surface and it could be detected in the gas phase. Similar results were reported by Rekoske et al. [17]. The authors have investigated the competition between the adsorption of acetaldehyde and of crotonaldehyde on rutile surfaces and figured out that the evolved crotonaldehyde could be readily displaced through continuous exposure of acetaldehyde. However, these authors claimed that crotonaldehyde cannot be formed on anatase surfaces.

For a better understanding of the processes occurring under dry and humid conditions, the experiment shown in Figure 2 was repeated and a $\mathrm{TiO}_{2}$ film was treated with a gas flow of $1000 \mathrm{ppb}$ of acetaldehyde, under dry conditions. A constant low amount of $700 \mathrm{ppb}$ acetaldehyde was observed again (see Figure 5) evincing that acetaldehyde was adsorbed on the $\mathrm{TiO}_{2}$ surface where it reacted to the crotonaldehyde. Hence, crotonaldehyde and acetaldehyde were present on the surface. When the gas flow was changed to the bypass mode, the concentration of acetaldehyde increased to the initial value again. Water was subsequently added to a washing flask to generate a humidified gas flow that was directed over the anatase film again. The concentration of acetaldehyde increased drastically to $6 \mathrm{ppm}(6000 \mathrm{ppb})$ indicating a favorable adsorption of water on the anatase surface which resulted in a desorption of acetaldehyde molecules from the surface. After $2 \mathrm{~h}$, the concentration decreased again to the initial value of $1 \mathrm{ppm}(1000 \mathrm{ppb})$. Hence, in the humid conditions, crotonaldehyde was not generated due to the minor adsorption of acetaldehyde molecules, which were not able to react with each other (see Figure 6). 


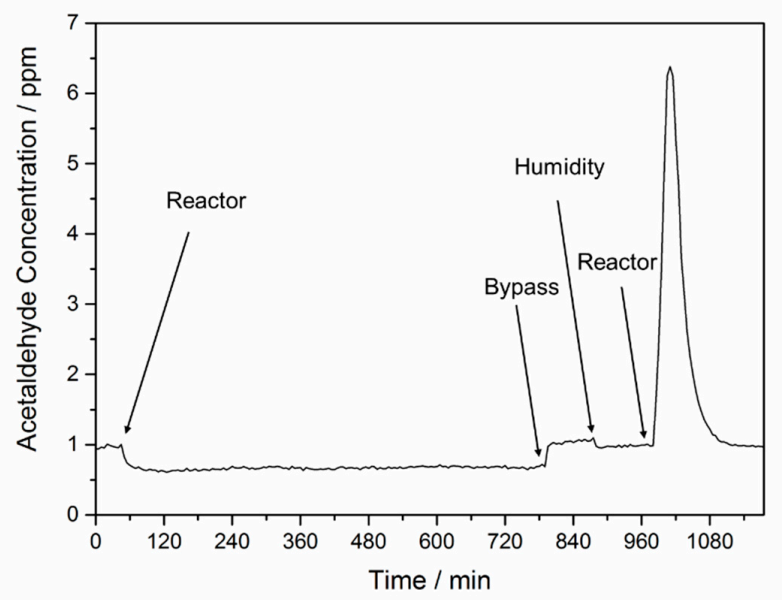

Figure 5. The concentration of acetaldehyde as a function of time obtained in the dark. Firstly, an anatase film was treated with acetaldehyde, under dry conditions. A decrease in the concentration of acetaldehyde was observed when the gas flow was directed into the reactor. Under humidified conditions, the concentration of acetaldehyde detected at the gas outlet increased to $6 \mathrm{ppm}$, before it decreased to the initial value of 1 ppm again.

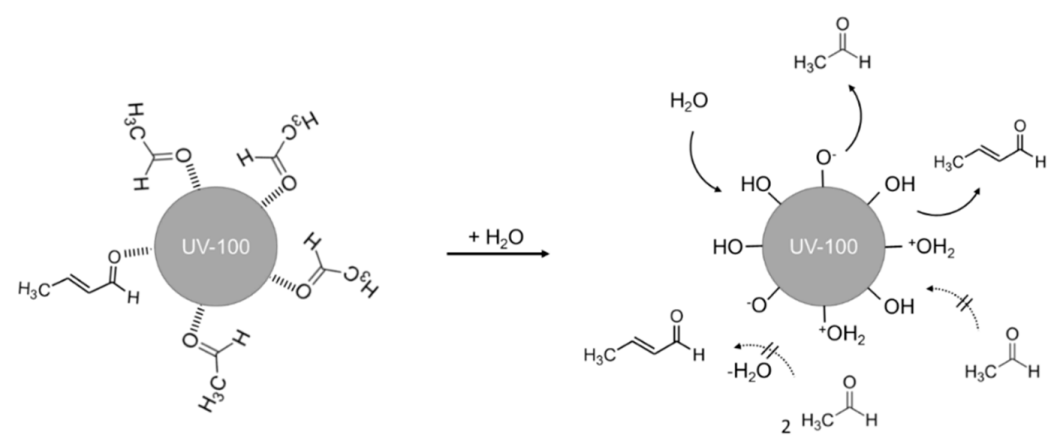

Figure 6. On the left side, the adsorption of acetaldehyde and crotonaldehyde is shown under dry conditions. Under humidified conditions, acetaldehyde was desorbed from the surface and was replaced by $\mathrm{H}_{2} \mathrm{O}$ molecules. Crotonaldehyde was not formed anymore, because only a minor amount of acetaldehyde was adsorbed.

For verification of the latter results, and to prove the desorption of acetaldehyde and crotonaldehyde from the anatase surface in the presence of water vapor, ATR-FTIR spectra were recorded of a $\mathrm{TiO}_{2}$ layer. For this purpose, a $\mathrm{TiO}_{2}$ film was purged with acetaldehyde, in air, for $2 \mathrm{~h}$, in the dark. Figure 7 shows the expected bands characteristic for acetaldehyde and crotonaldehyde. After the adsorption of acetaldehyde and the formation of crotonaldehyde, water was added to the washing flask to generate a humidified gas flow. The bands of acetaldehyde and crotonaldehyde decreased rapidly within five minutes, indicating a fast desorption of acetaldehyde and crotonaldehyde from the anatase surface. Hence, the adsorption of acetaldehyde on anatase surfaces was reversible, because acetaldehyde and crotonaldehyde could be easily replaced by water molecules. Batault et al. [10]. reported that acetaldehyde adsorption, under dry conditions, mostly occurred irreversibly on the $\mathrm{P} 25$ surface. However, these authors heated their $\mathrm{TiO}_{2}$ samples to $400{ }^{\circ} \mathrm{C}$, before each experiment, consequently, decreasing the number of surface hydroxyl groups. In this study the $\mathrm{TiO}_{2}$ film was prepared at ambient temperature, therefore, the number of surface hydroxyl groups should be higher. Batault et al. [10] also reported that under $50 \% \mathrm{RH}$, the adsorption on P25 only occurred as a reversible physical adsorption. The total surface hydroxylation prevented acetaldehyde to adsorb, irreversibly, since a complete surface hydroxylation already occurred below a $\mathrm{RH}$ of $10 \%$ [19]. With regards to the reaction mechanism for the crotonaldehyde formation proposed by Singh et al. [8], the acetaldehyde molecules needed to be adsorbed through the carbonyl group $\mathrm{C}=\mathrm{O}$ 
to the Ti atoms, in order to react with each other. However, when the surface was hydroxylated and water was adsorbed, the carbonyl group $\mathrm{C}=\mathrm{O}$ of acetaldehyde molecules was not able to interact with the Ti-atoms. El-Maazawi et al. [20] discovered the formation of mesityl oxide from acetone, both in the presence and in the absence of $\mathrm{H}_{2} \mathrm{O}$, in the dark. In the presence of $\mathrm{H}_{2} \mathrm{O}$, a minor amount of mesityl oxide was generated, which the authors explained by the fact that water was a product of the aldol condensation, therefore its presence did not favor the formation of mesityl oxide.

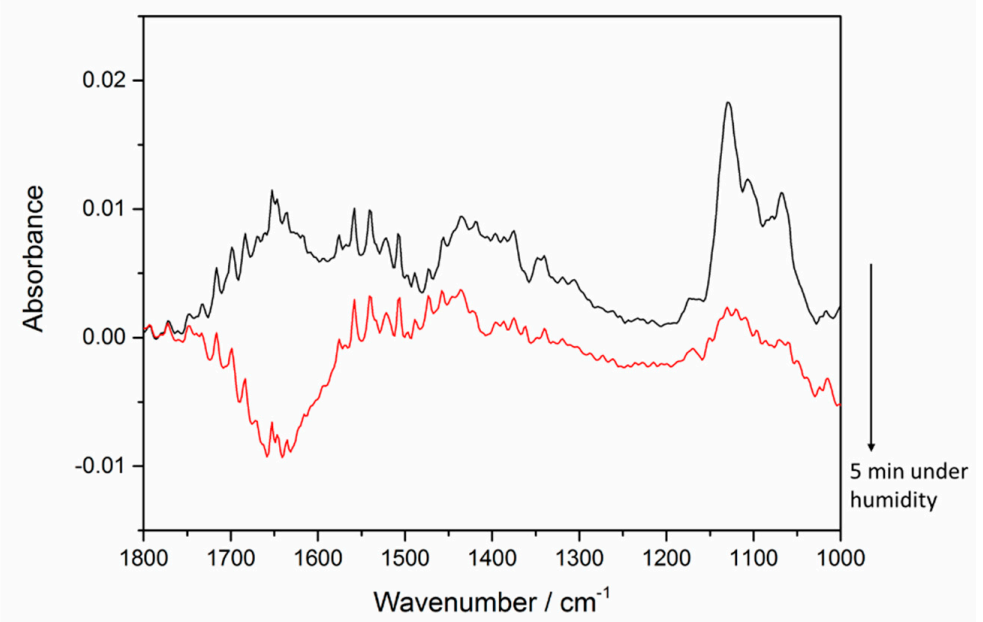

Figure 7. ATR-FTIR spectra recorded after purging an anatase film with acetaldehyde for $2 \mathrm{~h}$, under dry conditions (black). In the presence of humidity, the band's characteristics for acetaldehyde and crotonaldehyde decreased in intensity, within $5 \mathrm{~min}$, indicating a desorption of both molecules (red).

The following adsorption and degradation experiments of acetaldehyde, over $\mathrm{TiO}_{2}$, in the presence and absence of $\mathrm{O}_{2}$, were performed under dry conditions, because ATR-FTIR spectra of acetaldehyde and crotonaldehyde could be recorded, while under humidity, bands of acetaldehyde and crotonaldehyde did not appear.

\subsection{Effect of $\mathrm{O}_{2}$ on the Adsorption and Degradation of Acetaldehyde}

For investigations concerning the effect of $\mathrm{O}_{2}$ on the adsorption of acetaldehyde, the concentration of acetaldehyde as a function of time was monitored, after acetaldehyde had been directed over a $\mathrm{TiO}_{2}$ film, in the presence of $\mathrm{O}_{2}$ (Figure S3, left) and its absence (Figure S3, right). We have calculated that $5.8 \times 10^{16} / \mathrm{cm}^{2}$ acetaldehyde molecules were adsorbed on the $\mathrm{TiO}_{2}$ surface at the steady-state conditions, in the dark. Furthermore, ATR-FTIR spectra were recorded during acetaldehyde treatment of $\mathrm{TiO}_{2}$ in $\mathrm{O}_{2}$ (Figure S4, left) and in $\mathrm{N}_{2}$ (Figure S4, right) atmosphere. As expected $\mathrm{O}_{2}$ did not have an effect on the adsorption of acetaldehyde, ATR-FTIR spectra, as well as gaseous analysis revealed similar curve progressions in the $\mathrm{O}_{2}$ and the $\mathrm{N}_{2}$ atmosphere.

After the gaseous acetaldehyde treatment in the dark, the samples were illuminated by UV light, for $6 \mathrm{~h}$, in the $\mathrm{O}_{2}$ and in the $\mathrm{N}_{2}$ atmosphere. The corresponding curves, showing the concentration of acetaldehyde as a function of time are displayed in Figure 8 in the presence (left) and in the absence of $\mathrm{O}_{2}$ (right). In both, the $\mathrm{O}_{2}$ and the $\mathrm{N}_{2}$ atmosphere, the concentration of acetaldehyde decreased from $700 \mathrm{ppb}$ to $580 \mathrm{ppb}$, in the beginning, indicating a degradation of acetaldehyde by $\mathrm{TiO}_{2}$. In the presence of $\mathrm{O}_{2}$, the concentration remained at a constant low, during the UV illumination, thereby evincing a steady decomposition of acetaldehyde, in the $\mathrm{O}_{2}$ atmosphere. After $6 \mathrm{~h}$ of UV illumination, the lamp was turned off and the acetaldehyde concentration increased again. In the $\mathrm{N}_{2}$ atmosphere, a different trend was observed. While in the beginning, the concentration of acetaldehyde was as low as in the $\mathrm{O}_{2}$ atmosphere, it increased with increasing illumination time. When the UV lamp was turned off again, the concentration rose further. 

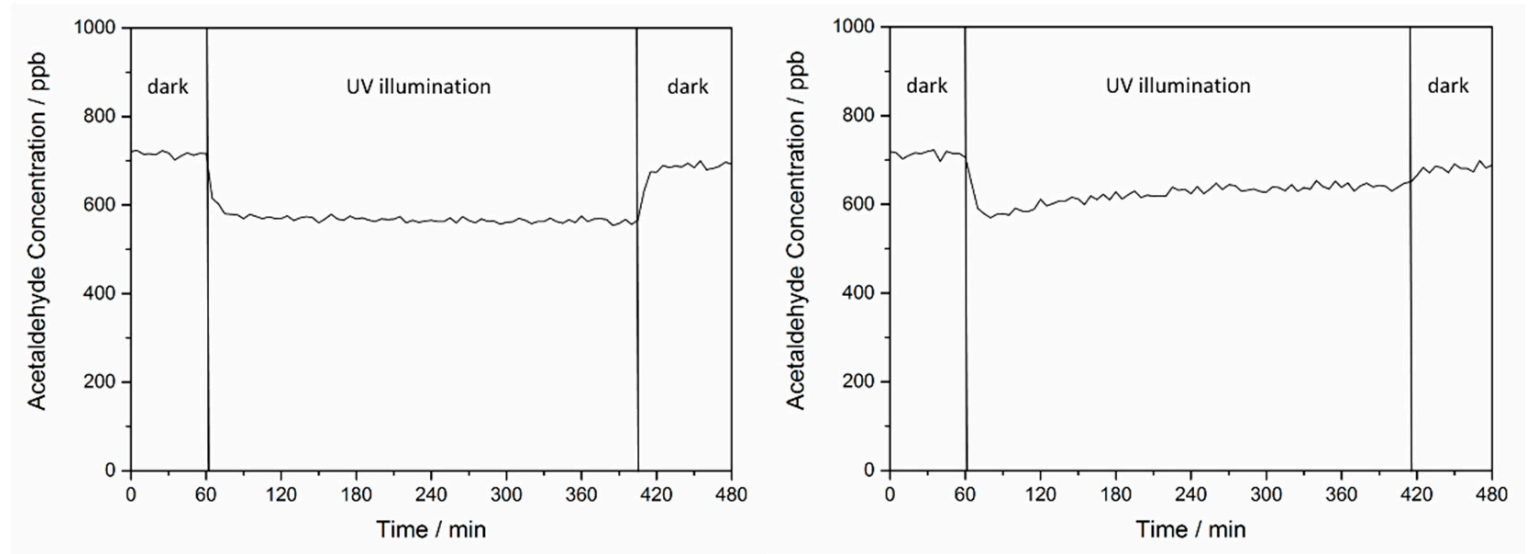

Figure 8. Acetaldehyde concentration as a function of time upon UV illumination in $\mathrm{O}_{2}(\mathbf{l e f t})$ and $\mathrm{N}_{2}$ (right) atmosphere.

ATR-FTIR spectra (Figure 9) of a $\mathrm{TiO}_{2}$ film, treated with acetaldehyde, were recorded in the presence (left) and in the absence (right) of $\mathrm{O}_{2}$, during $6 \mathrm{~h}$ of UV illumination, in order to understand the different kinetic curves obtained for the acetaldehyde concentration in the $\mathrm{O}_{2}$ and in the $\mathrm{N}_{2}$ atmosphere (Figure 8). Both graphs show a decrease in the intensity of the bands characteristic for the acetaldehyde and the crotonaldehyde, indicating a decomposition of these molecules. Simultaneously, new bands appeared which increased in intensity, during the illumination time. In Table 2 the observed vibrational frequencies are displayed and correlated with the mode assignments of the intermediates formed during the decomposition of acetaldehyde. Both graphs show bands characteristic for the formate and the acetate/acetic acid formation. The bands of the $v_{\mathrm{s}}(\mathrm{COO})$ and $v_{\mathrm{as}}(\mathrm{COO})$ of acetate, as well as the $v(\mathrm{C}=\mathrm{O})$ of acetic acid, show similar trends in intensity, in the $\mathrm{O}_{2}$ and $\mathrm{N}_{2}$ atmosphere. When comparing the intensity of the $v_{\mathrm{s}}(\mathrm{COO})$ and $v_{\mathrm{as}}(\mathrm{COO})$ bands of formate, a difference was observed in the $\mathrm{O}_{2}$ and the $\mathrm{N}_{2}$ atmosphere. While during the first 30 min of illumination the bands were similar (black to purple), afterward, they showed a higher increase in intensity in the $\mathrm{O}_{2}$ atmosphere, than in the $\mathrm{N}_{2}$ atmosphere. Therefore, under oxygenic conditions, a decomposition from the acetate/acetic acid to formate occurred, while under $\mathrm{N}_{2}$, the formation was suppressed and the acetate/acetic acid accumulated on the surface. In the absence of $\mathrm{O}_{2}$, surface-adsorbed $\mathrm{O}_{2}$ was consumed for the formation of the acetate and the formate, in the first $30 \mathrm{~min}$ of illumination. When the adsorbed $\mathrm{O}_{2}$ was consumed, only a small amount of acetaldehyde was decomposed into the formate. In the presence of $\mathrm{O}_{2}$, acetate was decomposed into the formate, as indicated by an increase of the $v_{s}(\mathrm{COO})$ and $v_{\mathrm{as}}(\mathrm{COO})$ bands of the formate, with the illumination time.
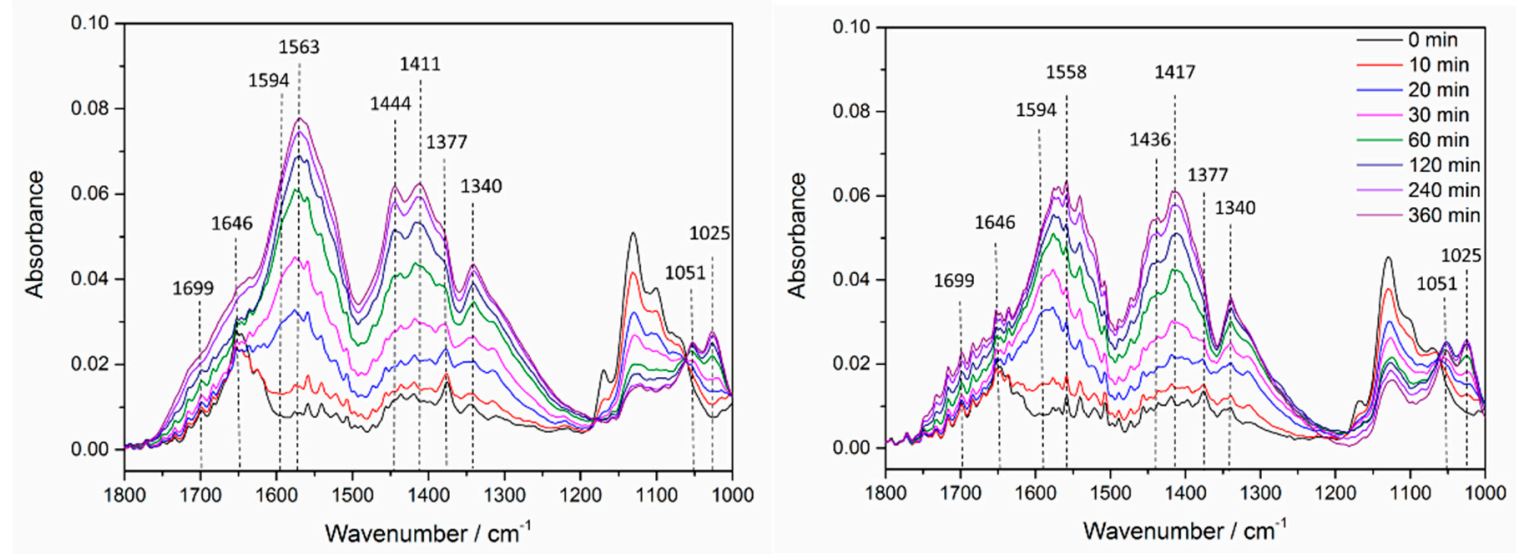

Figure 9. ATR-FTIR spectra of a $\mathrm{TiO}_{2}$ film recorded during gaseous treatment of acetaldehyde in $\mathrm{O}_{2}$ (left) and $\mathrm{N}_{2}$ (right) atmosphere, upon UV-illumination, for $6 \mathrm{~h}$. 
Table 2. Vibrational frequencies and mode assignments of the observed FTIR bands $\left(\mathrm{cm}^{-1}\right)$ during the acetaldehyde treatment of an anatase film, upon UV illumination.

\begin{tabular}{cc}
\hline Position/cm & Assignment $[21-25]$ \\
\hline 1025 & $\rho\left(\mathrm{CH}_{3}\right) \mathrm{CH}_{3} \mathrm{COO}^{-}$ \\
1051 & $v(\mathrm{C}-\mathrm{C}) \mathrm{CH}_{3} \mathrm{COO}^{-}$ \\
1340 & $v_{\mathrm{s}}(\mathrm{COO}) \mathrm{HCOO}^{-}$ \\
1377 & $v(\mathrm{C}-\mathrm{H}) \mathrm{HCOO}^{-}$ \\
$1411 / 1417$ & $\delta\left(\mathrm{CH}_{3}\right) \mathrm{CH}_{3} \mathrm{COO}^{-}$ \\
$1436 / 1444$ & $v_{\mathrm{s}}(\mathrm{COO}) \mathrm{CH}_{3} \mathrm{COO}^{-}$ \\
$1558 / 1563$ & $v_{\mathrm{as}}(\mathrm{COO}) \mathrm{CH}_{3} \mathrm{COO}^{-}$ \\
1594 & $v_{\mathrm{as}}(\mathrm{COO}) \mathrm{HCOO}^{-}$ \\
1646 & $\delta\left(\mathrm{H}_{2} \mathrm{O}\right)$ \\
1699 & $v(\mathrm{C}=\mathrm{O}) \mathrm{CH}_{3} \mathrm{COOH}$ \\
\hline
\end{tabular}

For a better understanding of the reaction mechanism for the photocatalytic degradation of acetaldehyde in the absence of $\mathrm{O}_{2}$, the evolved gaseous products were detected by MS. For that purpose, a $\mathrm{TiO}_{2}$ film was treated with $50 \mathrm{ppm}$ of acetaldehyde, upon UV illumination and the gas at the outlet was constantly analyzed by MS. Figure S5 demonstrates the QMS signal, as a function of time of the masses $44 \mathrm{~m} / z$ and $16 \mathrm{~m} / z$, corresponding to $\mathrm{CO}_{2}$ and $\mathrm{CH}_{4}$. Both QMS signals increased upon UV illumination and decreased again when the UV light was turned off.

A schematic illustration of the intermediates formed in the $\mathrm{O}_{2}$ and the $\mathrm{N}_{2}$ atmosphere was presented in Figure 10. When correlating the ATR-FTIR results with the acetaldehyde concentration vs. time curves, it was concluded that during the first $30 \mathrm{~min}$ of illumination the decomposition of acetaldehyde was similar in the $\mathrm{O}_{2}$ and in the $\mathrm{N}_{2}$ atmosphere. Both showed a decrease in the concentration of acetaldehyde and the formation of acetate and formate. In the $\mathrm{N}_{2}$ atmosphere, surface adsorbed $\mathrm{O}_{2}$ was consumed for the decomposition of acetaldehyde, to form acetate and formate, while in the $\mathrm{O}_{2}$ atmosphere there was an adequate amount of $\mathrm{O}_{2}$ available from the gas phase for the degradation of acetaldehyde. After $30 \mathrm{~min}$, upon UV illumination in the presence of $\mathrm{O}_{2}$, a constant low amount of acetaldehyde was observed. The ATR-FTIR spectra revealed a decomposition of acetaldehyde forming both formate and acetic acid/acetate, because a sufficiently high amount of $\mathrm{O}_{2}$ was available for the decomposition of acetaldehyde. In contrast to that, after $30 \mathrm{~min}$, a depletion of $\mathrm{O}_{2}$ occurred in the $\mathrm{N}_{2}$ atmosphere, because most of the surface adsorbed $\mathrm{O}_{2}$ was consumed. As can be seen from the ATR-FTIR spectra, at the beginning of the illumination time, the band at $\sim 1560 \mathrm{~cm}^{-1}$ showed a higher intensity than the band at $\sim 1400 \mathrm{~cm}^{-1}$, because both acetate and formate were generated. At longer illumination times, the intensities of the bands became equal, since acetate was no longer decomposed into formate, due to the depletion of $\mathrm{O}_{2}$. Acetate was rather accumulated on the surface and the degradation of acetaldehyde was suppressed. Therefore, the concentration of acetaldehyde detected, after passing the $\mathrm{TiO}_{2}$ film increased. However, acetate was also degraded to a small extent, forming $\mathrm{CH}_{4}$ and $\mathrm{CO}_{2}$, in the absence of $\mathrm{O}_{2}$.

In Figure 11, a reaction mechanism is proposed to explain the formation of acetate in the absence of $\mathrm{O}_{2}$. Acetaldehyde was adsorbed on the $\mathrm{TiO}_{2}$ surface through its oxygen lone pair to a $\mathrm{Ti}^{\mathrm{IV}}$ center. Upon UV illumination, a proton in the $\alpha$-position of acetaldehyde was abstracted by a bridging-oxygen, resulting in the formation of a surface hydroxyl species. The neighboring bridging-oxygen (Figure 11, red) atom of the $\mathrm{Ti}^{\mathrm{IV}}$ center was consumed for the formation of an acetate molecule.

In the future, isotopic studies on the degradation of acetaldehyde, using $\mathrm{Ti}^{18} \mathrm{O}_{2}$, will be done. Here, the evolved $\mathrm{CO}_{2}$ should contain ${ }^{18} \mathrm{O}$, in order to prove the assumption that lattice oxygen was involved in the formation of acetate. El-Maazawi et al. [20] and Szanyi et al. [26] investigated the degradation of acetone, in the presence and in the absence of $\mathrm{O}_{2}$, and reported that under oxygenic conditions acetone was completely degraded to $\mathrm{CO}_{2}$, while in the absence of $\mathrm{O}_{2}$, acetate and formate formation proceeded only to a limited extent. Furthermore, when $\mathrm{O}_{2}$ was depleted, acetate and formate were accumulated on the $\mathrm{TiO}_{2}$ surface, and there was not any (or very limited) complete decomposition, 
forming $\mathrm{CO}_{2}$. These authors proposed that lattice oxygen was involved in the mineralization of acetone. Montoya et al. [27] investigated the photocatalytic degradation of benzene, under anaerobic conditions, employing $\mathrm{Ti}^{18} \mathrm{O}_{2}$ as photocatalyst and they were able to show that the evolved $\mathrm{CO}_{2}$ contained lattice ${ }^{18} \mathrm{O}$ atoms from $\mathrm{Ti}^{18} \mathrm{O}_{2}$.

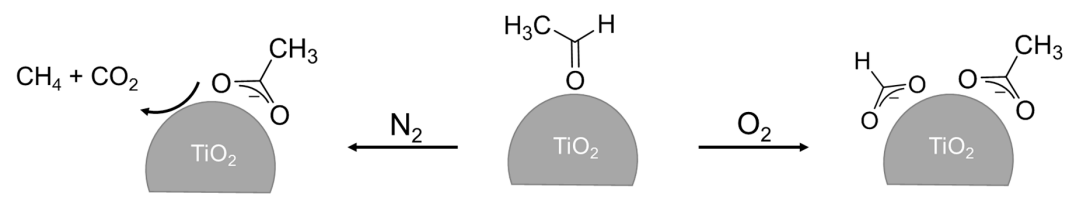

Figure 10. Schematic illustration of the different intermediates formed from acetaldehyde on the anatase surface, and in the gas phase in the $\mathrm{O}_{2}$ and the $\mathrm{N}_{2}$ atmosphere, observed by ATR-FTIR and MS.

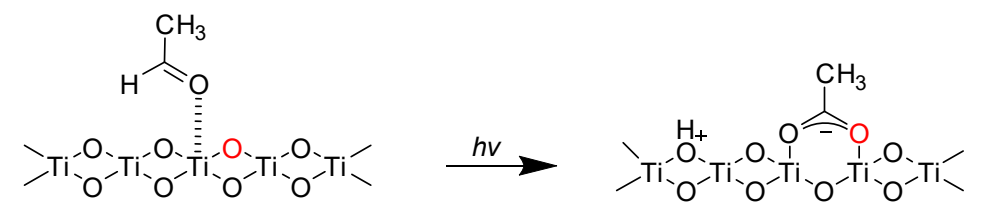

Figure 11. Proposed reaction mechanism of the acetaldehyde reaction with bridging-oxygen atoms to form acetate, in the absence of $\mathrm{O}_{2}$.

\section{Materials and Methods}

\subsection{Materials}

The commercial $\mathrm{TiO}_{2}$ photocatalyst Hombikat UV-100, containing $100 \%$ anatase (XRD pattern is shown in Figure S6, BET surface $280 \mathrm{~m}^{2} / \mathrm{g}$ ), was provided by Sachtleben Chemie GmbH (Duisburg, Germany). Acetaldehyde gas, containing $251 \mathrm{ppm}$ in $\mathrm{N}_{2}$, was supplied by the Linde Gas AG (Munich, Germany).

\section{2. $\mathrm{TiO}_{2}$ Film Preparation}

For the ATR-FTIR measurement, a suspension of $5.75 \mathrm{~g} \mathrm{~L}^{-1} \mathrm{UV}-100$, in deionized water, was sonicated for $15 \mathrm{~min}$, in an ultrasonic bath. Afterward, an aliquot of $400 \mu \mathrm{L}$ was placed on a $\mathrm{ZnSe}$ crystal and was distributed by gently balancing the crystal. The crystal had a size of $6.8 \times 72 \mathrm{~mm}$ with an area of $490 \mathrm{~mm}^{2}$. After evaporation of the water, a homogeneous film was obtained which had a particle layer of $2.3 \mathrm{~g} \mathrm{~m}^{-2}$ and a thickness of $1.7 \pm 0.3 \mu \mathrm{m}$, according to Hug and Sulzberger [28].

For the acetaldehyde degradation measurements, the powder was pressed into a poly(methyl methacrylate) (PMMA) holder with an average size of $4.3 \times 4.3 \mathrm{~cm}$. The resulting pellet had a surface size of $18.49 \mathrm{~cm}^{2}$ and was pre-illuminated by UV light ( $365 \mathrm{~nm}, 1 \mathrm{~mW} / \mathrm{cm}^{2}$, Philips CLEO 100W-R), for at least $24 \mathrm{~h}$, in order to eliminate organic residues from the surface.

For the measurements using MS, an aliquot of $4 \mathrm{~mL}$ of a UV-100 suspension $\left(5.75 \mathrm{~g} \mathrm{~L}^{-1}\right)$ was placed into a PMMA holder with a size of $4.3 \times 9.2 \mathrm{~cm}$. After evaporation of the $\mathrm{H}_{2} \mathrm{O}$, a homogeneous film was obtained.

\subsection{ATR-FTIR Spectroscopy}

ATR-FTIR spectra were recorded on a Bruker IFS 66 equipped, with a deuterated triglycine sulfate (DTGS) detector, and an internal reflection element made of $\mathrm{ZnSe}$, with an angle of incidence of $45^{\circ}$, and 9 reflections on the upper face. The interferometer and the infrared light path in the spectrometer were constantly purged with argon, in order to avoid $\mathrm{H}_{2} \mathrm{O}$ and $\mathrm{CO}_{2}$ contamination. Each spectrum was an average of 300 scans, with a resolution of $4 \mathrm{~cm}^{-1}$. Before each experiment, a sequence of spectra taken, in the dark, for $2 \mathrm{~h}$, and upon UV illumination, for $6 \mathrm{~h}$, without acetaldehyde, were recorded. These spectra were used as blank reference spectra. After the blank spectra had been monitored, 
spectra in the dark $(2 \mathrm{~h})$ and upon UV illumination $(6 \mathrm{~h})$, with acetaldehyde, were recorded. The final spectra were obtained by subtraction of the blanks from the ones in the presence of the acetaldehyde.

For experiments under humidity $(58 \%), \mathrm{O}_{2}$ was directed through a washing flask to generate a humidified gas flow. An LED lamp (LED Flächenstrahler, Omicron-Laserage, Rodgau-Dudenhofen, Germany) was used as the UV illumination source, which had a maximum emission wavelength of $365 \mathrm{~nm}$, and an intensity of $1 \mathrm{~mW} \mathrm{~cm}{ }^{-2}$. The gas flow was set to $100 \mathrm{~mL} \mathrm{~min}^{-1}$ and was controlled by mass flow controllers (SIERRA ${ }^{\circledR}$, Monterey, CA, USA). The acetaldehyde concentration was maintained at $63 \mathrm{ppm}$. A closed compartment made of Plexi-Glass ${ }^{\circledR}$ (PMMA, Polymethylmethacrylate) was built and attached to the upper part of the ZnSe crystal, in order to generate a continuous gas flow (see Figure S7). The PMMA holder did not affect the photodegradation of acetaldehyde, because a contact did not exist between the reactor and the $\mathrm{TiO}_{2}$ film.

\subsection{Acetaldehyde Degradation}

The experimental set-up to monitor the concentration of acetaldehyde, as a function of time, is illustrated in Figure S8. UV-100 was treated with 1 ppm acetaldehyde, in $\mathrm{O}_{2}$ and in the $\mathrm{N}_{2}$ atmosphere. The gas flow was set to $1 \mathrm{~L} \mathrm{~min}^{-1}$ and was controlled by mass flow controllers (Brooks Instruments, Hatfield, PA, USA). For experiments under 50\% humidity, air was directed through a washing flask. After passing the reactor, which was made of PMMA, the gas was analyzed, every $5 \mathrm{~min}$, by a gas chromatograph equipped with a photoionization detector (GC/PID, SYNTECH Spectras GC 955, Groningen, Netherlands). The concentration of acetaldehyde was monitored for $2.5 \mathrm{~h}$, in the dark, and for $6 \mathrm{~h}$, upon UV illumination. The light source used was a Philips CLEO compact fluorescent tube and had an emission wavelength of $\lambda_{\max }=365 \mathrm{~nm}$ and an intensity of $1 \mathrm{~mW} \mathrm{~cm}^{-2}$.

\subsection{Mass Spectrometry}

The experimental set-up for the detection of gaseous products is illustrated in Figure S9. Herein, a UV-100 film, placed in a reactor made of PMMA, was treated with $50 \mathrm{ppm}$ of acetaldehyde in $\mathrm{N}_{2}$, for $2 \mathrm{~h}$, in the dark, and for $6 \mathrm{~h}$, upon UV illumination. The gas flow was set to $75 \mathrm{~mL} \mathrm{~min}^{-1}$ (SIERRA $^{\circledR}$, Monterey, CA, USA) and was constantly analyzed by a mass spectrometer at the outlet (Hiden HPR-20, Warrington, United Kingdom). An LED lamp (Flächenstrahler, Omicron-Laserage, Rodgau-Dudenhofen, Germany) with an intensity of $1 \mathrm{~mW} \mathrm{~cm}{ }^{-2}$ was used as the UV illumination source.

\section{Conclusions}

In this study, the effect of $\mathrm{O}_{2}$ and $\mathrm{H}_{2} \mathrm{O}$ on the adsorption and the photocatalytic degradation of acetaldehyde, in the presence of $\mathrm{TiO}_{2}$, were investigated at ambient temperatures. In the dark, the adsorption of acetaldehyde and the formation of crotonaldehyde were detected, both in $\mathrm{O}_{2}$ and in the $\mathrm{N}_{2}$ atmosphere, by ATR-FTIR spectroscopy. On the anatase surface, crotonaldehyde was formed by an aldol condensation of two acetaldehyde molecules. When using a continuous acetaldehyde gas flow, the concentration of acetaldehyde was constantly lowered, after passing the $\mathrm{TiO}_{2}$ film, because the generated crotonaldehyde was desorbed from the surface and was replaced by new acetaldehyde molecules reacting again with each other, to form crotonaldehyde. When using a humidified acetaldehyde gas flow, such a constantly lowered concentration was not observed. Under these conditions, the formation of crotonaldehyde was limited, because water was more favorably adsorbed on the anatase surface, as compared to acetaldehyde. Therefore, the possibility of the two acetaldehyde molecules reacting with each other to form crotonaldehyde on the anatase surface was significantly decreased.

Upon UV illumination both, acetaldehyde and crotonaldehyde were degraded. At the beginning of the illumination time, the results under the $\mathrm{O}_{2}$ and the $\mathrm{N}_{2}$ atmosphere showed similar trends. Both acetate and formate were detected on the surface. It was proposed that adsorbed $\mathrm{O}_{2}$ was consumed for the decomposition of acetaldehyde to form acetate and formate, in the $\mathrm{N}_{2}$ atmosphere. After $1 \mathrm{~h}$ 
of illumination, a depletion of $\mathrm{O}_{2}$ occurred and the rate of formate formation decreased. Acetate was not decomposed to formate, anymore, but accumulated on the $\mathrm{TiO}_{2}$ surface, instead. Thus, the concentration of acetaldehyde in the gas phase increased, because acetaldehyde was incompletely degraded, in the absence of a sufficient amount of $\mathrm{O}_{2}$. It was proposed that the lattice oxygen atoms from the $\mathrm{TiO}_{2}$ matrix were consumed for the formation of acetate, in the presence of $\mathrm{N}_{2}$. In the presence of $\mathrm{O}_{2}$ the concentration of acetaldehyde was constantly low, since $\mathrm{O}_{2}$ was present in high concentrations, and therefore acetaldehyde was readily decomposed to acetate and formate, as was detected by ATR-FTIR.

Supplementary Materials: The following are available online at http:/ / www.mdpi.com/2073-4344/8/10/417/s1, Figure S1: Acetaldehyde concentration as a function of time in the $\mathrm{O}_{2}$ atmosphere in the dark. Figure S2: Time evolution of the QMS signal of the mass $41 \mathrm{~m} / z$ corresponding to crotonaldehyde. Figure S3: Comparison between the acetaldehyde concentration as a function of time in $\mathrm{O}_{2}$ (left) and in $\mathrm{N}_{2}$ (right) atmosphere in the dark. Figure S4: ATR-FTIR spectra recorded during gaseous treatment of acetaldehyde over an anatase film in $\mathrm{O}_{2}$ (left) and $\mathrm{N}_{2}$ (right) atmosphere for two hours in the dark. Figure S5: QMS signal as a function of the time of the masses $16 \mathrm{~m} / \mathrm{z}$ and $44 \mathrm{~m} / z$ corresponding to $\mathrm{CH}_{4}$ and $\mathrm{CO}_{2}$. Figure S6: XRD pattern of UV-100. Figure S7: Experimental setup for the ATR-FTIR measurement. Figure S8: Experimental set up to monitor the concentration of acetaldehyde as a function of time. Figure S9: Experimental set up for the detection of gaseous products generated during acetaldehyde treatment of a UV-100 film in the dark and upon UV illumination.

Author Contributions: S.M. performed experiments; S.M. and J.S. wrote the manuscript; scientific support: A.V.E. and D.W.B.; Supervision: D.W.B.

Funding: This work was funded by the German Federal Ministry of Education and Research (contract No. 13N13350, PureBau-Untersuchung von Werkstoffsystemen für photokatalytisch hocheffiziente Baustoffe-Teilvorhaben: Oberflächenchemie der Photokatalysatoren und der Werkstoffe). A.V.E. and D.W.B. acknowledge the support by a Mega-grant of the Government of the Russian Federation within the Project "Establishment of the Laboratory 'Photoactive Nanocomposite Materials'" No. 14Z50.31.0016. The publication of this article was funded by the Open Access fund of Leibniz Universität Hannover.

Acknowledgments: The authors wish to thank Sachtleben Chemie $\mathrm{GmbH}$ for providing the $\mathrm{TiO}_{2}$ material and Luis Granone for the XRD analysis.

Conflicts of Interest: The authors declare no conflict of interest.

\section{References}

1. Altshuller, A.P. Production of aldehydes as primary emissions and from secondary atmospheric reactions of alkenes and alkanes during the night and early morning hours. Atmos. Environ. Part A Gen. Top. 1993, 27, 21-32. [CrossRef]

2. European Agency for Safety and Health at Work. European Risk Observatory Report. Exploratory Survey of Occupational Exposure Limits for Carcinogens, Mutagens and Reprotoxic substances at EU Member States Level. 2009. Available online: https://osha.europa.eu/en/publications/reports/548OELs/view (accessed on 1 July 2017).

3. Occupational Safety and Health Administration (OSHA). Permissible Exposure Limits, Occupational Safety and Health Administration; OSHA: Washington, DC, USA, 2005.

4. Sopyan, I.; Watanabe, M.; Murasawa, S.; Hashimoto, K.; Fujishima, A. An efficient $\mathrm{TiO}_{2}$ thin-film photocatalyst: Photocatalytic properties in gas-phase acetaldehyde degradation. J. Photochem. Photobiol. A Chem. 1996, 98, 79-86. [CrossRef]

5. Atitar, M.F.; Belhadj, H.; Dillert, R.; Bahnemann, D.W. The Relevance of ATR-FTIR Spectroscopy in Semiconductor Photocatalysis. In Emerging Pollutants in the Environment-Current and Further Implications; Larramendy, M.L., Ed.; InTech: London, UK, 2015; pp. 203-229.

6. Mendive, C.B.; Bredow, T.; Blesa, M.A.; Bahnemann, D.W. ATR-FTIR measurements and quantum chemical calculations concerning the adsorption and photoreaction of oxalic acid on $\mathrm{TiO}_{2}$. Phys. Chem. Chem. Phys. 2006, 8, 3232-3247. [CrossRef] [PubMed]

7. Idriss, H.; Barteau, M.A. Selectivity and mechanism shifts in the reactions of acetaldehyde on oxidized and reduced $\mathrm{TiO}_{2}$ (001) surfaces. Catal. Lett. 1996, 40, 147-153. [CrossRef]

8. Singh, M.; Zhou, N.; Paul, D.K.; Klabunde, K.J. IR spectral evidence of aldol condensation: Acetaldehyde adsorption over $\mathrm{TiO}_{2}$ surface. J. Catal. 2008, 260, 371-379. [CrossRef] 
9. Hauchecorne, B.; Terrens, D.; Verbruggen, S.; Martens, J.A.; Van Langenhove, H.; Demeestere, K.; Lenaerts, S. Elucidating the photocatalytic degradation pathway of acetaldehyde: An FTIR in situ study under atmospheric conditions. Appl. Catal. B Environ. 2011, 106, 630-638. [CrossRef]

10. Batault, F.; Thevenet, F.; Hequet, V.; Rillard, C.; Le Coq, L.; Locoge, N. Acetaldehyde and acetic acid adsorption on $\mathrm{TiO}_{2}$ under dry and humid conditions. Chem. Eng. J. 2015, 264, 197-210. [CrossRef]

11. Ohko, Y.; Tryk, D.A.; Hashimoto, K.; Fujishima, A. Autoxidation of Acetaldehyde Initiated by $\mathrm{TiO}_{2}$ Photocatalysis under Weak UV Illumination. J. Phys. Chem. B 1998, 102, 2699-2704. [CrossRef]

12. Muggli, D.S.; McCue, J.T.; Falconer, J.L. Mechanism of the Photocatalytic Oxidation of Ethanol on $\mathrm{TiO}_{2}$. J. Catal. 1998, 173, 470-483. [CrossRef]

13. von Sonntag, C. Free-Radical-Induced DNA Damage and Its Repair; Schreck, S., Ed.; Springer: Berlin/Heidelberg, Germany, 2006.

14. Topalian, Z.; Stefanov, B.I.; Granqvist, C.G.; Österlund, L. Adsorption and photo-oxidation of acetaldehyde on $\mathrm{TiO}_{2}$ and sulfate-modified $\mathrm{TiO}_{2}$ : Studies by in situ FTIR spectroscopy and micro-kinetic modeling. J. Catal. 2013, 307, 265-274. [CrossRef]

15. Stefanov, B.I.; Topalian, Z.; Granqvist, C.G.; Österlund, L. Acetaldehyde adsorption and condensation on anatase $\mathrm{TiO}_{2}$ : Influence of acetaldehyde dimerization. J. Mol. Catal. A Chem. 2014, 381, 77-88. [CrossRef]

16. János, R.; Kiss, J. Adsorption and surface reactions of acetaldehyde on $\mathrm{TiO}_{2}, \mathrm{CeO}_{2}$ and $\mathrm{Al}_{2} \mathrm{O}_{3}$. Appl. Catal. A Gen. 2005, 287, 252-260.

17. Rekoske, J.E.; Barteau, M.A. Competition between Acetaldehyde and Crotonaldehyde during Adsorption and Reaction on Anatase and Rutile Titanium Dioxide. Langmuir 1999, 15, 2061-2070. [CrossRef]

18. Wu, W.-C.; Yang, S.-J.; Ho, C.-H.; Lin, Y.-S.; Liao, L.-F.; Lin, J.-L. Crotonaldehyde Formation from Decomposition of $\mathrm{ICH} 2 \mathrm{CH} 2 \mathrm{OH}$ on Powdered $\mathrm{TiO}_{2}$. J. Phys. Chem. B 2006, 110, 9627-9631. [CrossRef] [PubMed]

19. Coronado, J.M.; Zorn, M.E.; Tejedor-Tejedor, I.; Anderson, M.A. Photocatalytic oxidation of ketones in the gas phase over $\mathrm{TiO}_{2}$ thin films: A kinetic study on the influence of water vapor. Appl. Catal. B Environ. 2003, 43, 329-344. [CrossRef]

20. El-Maazawi, M.; Finken, A.N.; Nair, A.B.; Grassian, V.H. Adsorption and Photocatalytic Oxidation of Acetone on $\mathrm{TiO}_{2}$ : An in Situ Transmission FT-IR Study. J. Catal. 2000, 191, 138-146. [CrossRef]

21. Liao, L.-F.; Lien, C.-F.; Lin, J.-L. FTIR study of adsorption and photoreactions of acetic acid on $\mathrm{TiO}_{2}$. Phys. Chem. Chem. Phys. 2001, 3, 3831-3837. [CrossRef]

22. Busca, G. Infrared studies of the reactive adsorption of organic molecules over metal oxides and of the mechanisms of their heterogeneously-catalyzed oxidation. Catal. Today 1996, 27, 457-496. [CrossRef]

23. Liao, L.-F.; Wu, W.-C.; Chen, C.-Y.; Lin, J.-L. Photooxidation of Formic Acid vs Formate and Ethanol vs Ethoxy on $\mathrm{TiO}_{2}$ and Effect of Adsorbed Water on the Rates of Formate and Formic Acid Photooxidation. J. Phys. Chem. B 2001, 105, 7678-7685. [CrossRef]

24. Backes, M.J.; Lukaski, A.C.; Muggli, D.S. Active sites and effects of $\mathrm{H}_{2} \mathrm{O}$ and temperature on the photocatalytic oxidation of $13 \mathrm{C}$-acetic acid on $\mathrm{TiO}_{2}$. Appl. Catal. B Environ. 2005, 61, 21-35. [CrossRef]

25. Belhadj, H.; Hakki, A.; Robertson, P.K.J.; Bahnemann, D.W. In situ ATR-FTIR study of $\mathrm{H}_{2} \mathrm{O}$ and $\mathrm{D}_{2} \mathrm{O}$ adsorption on $\mathrm{TiO}_{2}$ under UV irradiation. Phys. Chem. Chem. Phys. 2015, 17, 22940-22946. [CrossRef] [PubMed]

26. Szanyi, J.; Kwak, J.H. Photo-catalytic oxidation of acetone on a $\mathrm{TiO}_{2}$ powder: An in situ FTIR investigation. J. Mol. Catal. A Chem. 2015, 406, 213-223. [CrossRef]

27. Montoya, J.F.; Ivanova, I.; Dillert, R.; Bahnemann, D.W.; Salvador, P.; Peral, J. Catalytic Role of Surface Oxygens in $\mathrm{TiO}_{2}$ Photooxidation Reactions: Aqueous Benzene Photooxidation with $\mathrm{Ti}^{18} \mathrm{O}_{2}$ under Anaerobic Conditions. J. Phys. Chem. Lett. 2013, 4, 1415-1422. [CrossRef]

28. Hug, S.J.; Sulzberger, B. In situ Fourier Transform Infrared Spectroscopy Evidence for the Formation of Several Different Surface Complexes of Oxalate on $\mathrm{TiO}_{2}$ in the Aqueous Phase. Langmuir 1994, 10, 3587-3597. [CrossRef]

(C) 2018 by the authors. Licensee MDPI, Basel, Switzerland. This article is an open access article distributed under the terms and conditions of the Creative Commons Attribution (CC BY) license (http:/ / creativecommons.org/licenses/by/4.0/). 